\title{
THE CASE OF JOHN KINSEL. II.
}

BY GEORGE B. CUTTEN, M.A., PH.D.

The summer following his graduation, he took an agency which required him to be away from home some of the time. During this time he was 'asleep' a week at a time, and thus met with some disagreeable experiences. One of these resulted in the breaking of the engagement between his fiancee and himself. He was in a neighboring town, working on his agency when he went to 'sleep.' The next move was to get beastly intoxicated, and then he boarded the train and went to see his sweetheart. She knew nothing of his trouble and naturally considered this a voluntary intoxication; but she considered also that he had been deceiving her, for she had not been told that he drank, and further considered it inconsistent with the ministry. Taken all together she immediately broke the engagement, and no explanations would suffice to atone for the way in which he presented himself on this occasion.

In the fall John entered the Divinity school, but on the advice of his physician he did not complete the first term, but returned to his home on the farm. Since that time he has spent most of his time at his home, working on the farm, and teaching school in his district. He has been away for short intervals on agencies of different kinds. He had one or two attacks of his abnormality while in the Divinity school, but after he returned home the attacks became less frequent, and of less duration when they did come, until in the spring following his graduation from college he had his last attack up to the present time.

John's eyes were a source of constant trouble to him, and probably contributed not a little to his other trouble. In the college town one oculist assisted in the frequent change of his glasses, enabling him to get 20-5oths vision. This treatment lasted from November IO, I894, to January II, 1897. The oculist who had most to do with this case resided in a neighboring town, not far from John's home. He has kindly sent 
the following details: " $\mathrm{My}$ acquaintance with Mr. Kinsel dates from October, $\mathrm{I} 883$, when he was eleven years old. The story was that he was always considered extremely near-sighted, from his evident bad distinct vision, and from his way of holding a book within a few inches of his eyes. A year before he came someone had discovered a whitish appearance of his pupils. I found both crystalline lenses somewhat opaque, especially at their posterior parts (posterior polar cataract). His vision was right eye $15-70$ ths of normal, and his left eye ro7oths. With his right eye he could read No. 6 (fair book) print, and with his left eye No. 16 (very large) print, at about six inches. I advised no treatment for six months, and that he should come again then to let me see what changes if any were going on.

"I next saw him April, I888, and found the changes were very slight for five years. At this time his vision was, for right eye 15-5oths, and for the left 15-80ths.

"Again I saw him in September, 1899, after his graduation from college. His vision at this time was, for right eye 207oths, and for the left 20-100ths, with convex glasses. I advised operation on the left eye by the method known as 'needling.' The first operation was done on November 6, 1899, and was followed by no unpleasant reaction. Three more operations were done on this eye at intervals, all without subsequent pain or trouble, and on December 18 , I900, I found vision of the left eye with appropriate glass - to take the place of the (dissolved) lens - was 20-3oths +, or almost normal; and he could read the finest type at ten inches. I realized, as he did not, the dangers he had so fortunately escaped, and inclined to advise him to be satisfied with one good eye ; but he insisted that the other one be operated on.

"On December 30, I900, I did the first operation on the right eye; there was no reaction. On March I, IgOI, I did the second. This made the fifth operation on him, and as there had been no reaction following any of them, I think I overestimated his resisting power, and in my desire to get on with a less number of operations than had been required for the other eye, I operated more freely than I had formerly done. As a 
result he had within twelve hours an attack of acute glaucoma, for which there is but one thing to do, viz., the operation of iridectomy. This stopped the fearful pain and quieted the inflammation, but left him with vision of only I-7oth in this eye due to the thickening of the lens capsule. I was unwilling to attempt further operation till March I, Igo2, when I made a section of the capsule, and on March 8, rgo2, he had vision of 20-50ths with prospect of further improvement.

"During the last year the vision of the right eye has fallen off to 20-7oths, owing to the thickening of the capsule. A recent needling operation has restored the vision to 20-40ths.

"These cases of posterior polar cataract are not usually considered favorable for operation, as they are apt to be accompanied by some diseased condition of the nerve. This in his case proved not to be so; certainly not in the left eye and I think not in the right one. They are not cases in which the conservative oculist often urges an operation, he usually waits until the patient demands it, as was the case with our friend. $\mathrm{He} *$ * was eager to make an experiment of his worst eye. I consented with some misgivings, and am glad now that I did."

As has been said, the abnormal states in their usual form stopped in the spring of 1898 , but in the fall of 1900 he developed a real dipsomania. Let us look at the alcoholic history of his case which has been reserved for this place. His heredity, which has been given, reveals that his maternal greatgrandfather, grandfather and great-uncles all drank heavily; but neither his mother nor any of her brothers or sisters drank. All the Kinsels drank, and there is a direct history of alcoholism on this side of the family as far as it can be traced. Add to this the unstable neurotic diathesis, and we have splendid soil for the development of dipsomania.

John drank cider at home when a boy, but was never intoxicated but once. When seven years of age, his mother being away, he climbed up in the pantry and took from the shelf some cider brandy and drank enough to intoxicate him. He never drank anything but cider and this cider brandy until he was fourteen, when he had a glass of beer. When twenty-one years old, being in the sophomore class in college, he drank on one 
occasion beer and wine, and on another occasion claret lemonade. On the former of these occasions he became 'happy.' The following summer he drank cider at home.

In the junior year he only drank when in these abnormal states. His beverage was mostly beer, very little of which would intoxicate him. During the summer vacation, between his junior and senior years, he drank nothing at all, not even the cider at home. In the senior year he drank a great deal, but only in the abnormal states, except that sometimes he would come out of the abnormal state into the normal, partially intoxicated; then he would continue drinking in the normal state. But never was drinking initiated in the normal state.

During the summer following graduation he drank twice in his abnormal state, and both times was very much intoxicated. In the autumn while in Divinity school he drank some, but not sufficient to cause intoxication. He knew that he had been drinking by the smell of beer on his breath when he awoke. This is very interesting in showing the severance of the two states, for normally we cannot smell anything that we have partaken. After leaving the Divinity school, in January of the following year, he drank some cider when normal as well as during the abnormal state. This was the first of a desire to drink when normal, and was gratified by cider. $\mathrm{He}$ also smoked very heavily during this time.

In April of that year, 1898 , he went fishing with some men who had wine and whiskey, and here we have the first voluntary intoxication. He drank cider all that summer and autumn, but not to intoxication, and continued very light or no drinking during the following winter, spring and summer. The following autumn, 1899 , he drank considerable cider, on one occasion sufficient to intoxicate him; he also got intoxicated on beer. The subsequent winter he got 'happy' several times on cider, drank cider all the spring and summer, and in the early fall developed a true dipsomania with monthly periods, which continued all the fall and winter, the last one being on March 19, rgor. During these periods whiskey or any intoxicants were drunk.

On March 20, he came to the writer for treatment. He had had two drinks that morning, but as he had previously been hyp- 
notized, and was an excellent subject, no difficulty was experienced in hypnotizing him. He slept deeply and appropriate suggestions were given. He came again on the following day and on April 16,17 and 18 , the last three being just previous to the time for his next outbreak. He went away and the next day the craving appeared on time, contrary to suggestion. He went to a saloon and procured a glass of beer, went to another saloon and got another glass. He went into a third saloon, purchased and drank a third glass of beer, when he began to know (he expressed it, " Hear, feel or remember, I can't tell which. It seemed like all three,") what I had suggested to him.

The next day he wrote very hurriedly as follows :

\section{Saturday.}

Dear Cutten: I won't come Monday, I believe I don't need any more treatments, that they would be harmful. I'll explain. Yesterday I was seized with a mighty desire to drink. I yielded. As I drank my third beer I became sick as a horse. I could hear your voice far away saying, "You cannot drink, it will make you vomit, you can't raise your hand to your head, it is impossible. You don't want it, you can't take it. You can't smoke, tobacco tastes like wormwood. You will be ambitious, * * Is this what you said? I seem to remember it all. Tell me if I had better be treated any more, or see if I remain in this state, this third self. Write to me and tell me what to do; I will come anytime you say if you think best.

\section{Yours sincerely, John Kinsel.}

P. S. The very thought of drink makes me heave. If this only lasts I will be a model man you may be sure. Do you think it will?

J. K.

On June 2, again, he came and was hypnotized. From that time until November, a period of six months - he did not touch any kind of intoxicating liquors, but then he got a quart of whiskey and became intoxicated. Since that time he has had no desire, and where the smell of liquor used to engender a 
great desire for a drink, now it has no effect, or if any, it causes a repugnance.

Mr. Kinsel very kindly allowed the writer to examine him while in the hypnotic condition, and some interesting results were obtained. When hypnotized, he was asked if this was the same state as his 'sleep'; he said that it was neither the same as his 'sleep' nor as his waking state, but a third state in which he could remember the events of both states. He was asked why he drank in the abnormal state, to which he replied: "When I was awake it seemed very wrong for me to drink, but when I went to sleep it not only seemed all right for me to do it, but the thing that I ought to do. It was the same way when these monthly spells came on (dipsomania)." We see here the change in the judgment, all scruples were removed, and it became a duty for him to drink where before it was a sin.

The hypnotic state was used by the writer to ascertain some facts concerning his case, but the statements were always verified, and it was found that most of the statements were correct; still he could not be trusted in everything that he said. An attempt was made to get a reproduction of the doggerel composed in the sophomore year, eight years previous, of which he could remember normally only twelve lines which had been told to him while he was awake. Not being familiar with the original, it was thought that he was showing a remarkable exaltation of memory, and in some respects he was; but it was also discovered that he could produce doggerel as well, and as rapidly in the hypnotic state as in his 'sleeping' state, and that he was interpolating much that did not belong in the original.

After finishing the doggerel, he said to the writer: "That's pretty bum poetry isn't it? You wouldn't hardly compare it to Homer." The writer replied that it was all right, when John made some further remarks. He was then asked if all that he had given was in the original, to which he replied, "Do you remember G-S-m-l" "Yes." "Well, he said, "Gentlemen, -ah- you -ah-did not get that from the text, but from the context.' Well, I did not get it all from the text but from the context. I changed the meter, but I can give it to you in any other meter, or any other damned old poem; I feel like making 
poetry this morning." The writer then said to him, "Make some poetry on our baby, any meter you like, and I will write it down." The last four lines are presented to show what he calls his best effort :

\footnotetext{
"And great big Cutten, noisy, strong, is happy when he hears the song That sings his baby into rest, asleep upon her mother's breast.

And Cutten moves so quiet, still, you'd think be'd hypnotized his will;

He fears he'll wake his little girl, and spoil the luster of his pearl."
}

He remarked after he had finished, "That's pretty bum. You hadn't ought to give me a subject like that, that's too good a subject. You hadn't ought to ask a man to write doggerel poetry on a baby. I tried to do well on that." These verses were spoken just as fast as they could be taken down, and on other occasions the rhymes were not recorded, and he talked right along without stopping with about the same success. There are three characteristics shown very plainly in his doggerel regarding the boat-sail. The first is the relative memory of the normal and abnormal states while hypnotized. While in the hypnotic condition he remembered all of the poem which he did in the normal state, and weaved it in. He remembered some of the poem as he used to recite it in the abnormal state, but not all of it; much more, however, than he could remember in the normal state. 'The second characteristic is the power of spontaneous versification while in the hypnotic state, as being equal to that of the abnormal state. The material which he composed at the time, he tried at first to pass off as the original. In the third place, it shows the vulgar state of mind when he is hypnotized. He is fully as vulgar in the hypnotic state as in the abnormal state, and very much more so in both these than in the normal state.

The second poem, that on the baby, shows what he called doing the very best he could in the way of rhyming; but in this as in the other there is a change of meter. Here, different from his usual mood in an abnormal state, the friendly and flattering way in which he speaks of the writer, is quite noticeable. It will be remembered that in the abnormal state he was usually sullen, and unkind with everyone, here we have the direct 
opposite. It shows the emotional extremes when not in the normal state.

Mr. Kinsel is at present teaching in a preparatory school. Apparently he is quite well, his eyes in the best condition they have been, and free from attacks of epilepsy, double personality, or dipsomania. Although the samples of his English given here while in the hypnotic condition, and just afterwards, were far from chaste, he has a remarkably fine appreciation of good English, and power of composition. He is also said to be a successful teacher.

\section{PART II.}

The statement was made in the beginning of Part $I$. that that part was wholly descriptive, and the terms there used were not intended to imply any theories. It remains for us now to discuss briefly a few points in the description. This discussion is not in the form of conclusions from the case, or theories in regard to the case, nor are such claimed for it; it is simply meant to be suggestive.

I. Attention is directed to the power of spontaneous versification of which some examples have been give. This abnormality - this genius - has shown itself in some quite famous persons, who have been otherwise quite normal. The following is quoted : ${ }^{1}$

"It seems highly probable that the extraordinary powers of impromptu versification shown by Theodore Hook and the late Mr. Serjeant Payne, were of the same intuitive kind as the faculty of musical improvisation. * I think it probable that if Mr. Hook or Mr. Payne had been asked the question, they would have said that their conscious mental participation in the performance was confined to that of a listener, and that they were wholly unable to say how it was produced, or to foresee the termination of a verse at the beginning of it."

Both in the cases quoted and in that of Mr. Kinsel, we see the exaltation of the normal faculties, in the power of attainment as well as in the rapidity of completion, so characteristic of abnormal conditions, e. g., hyperæsthesia of the senses, and histrionic skill of hypnotics. Mr. Kinsel was the most spontane-

'Thomas Beckwith, 'Duplex Personality,' Proc. Soc. Psy. Research, vi., 84. 
ous subject the writer has ever seen. Usually these subjects in the deeper stages are passive, answering at times unwillingly the questions or remarks addressed to them, but otherwise intent on sleep. This was not the case with John; he would volunteer remarks, make jokes, and laugh heartily on his own initiative.

2. If, as is probably true, the abnormal states were the equivalent of epileptic seizures, the dipsomaniacal attacks were the equivalent of the abnormal states, or better expressed, were another equivalent of the epileptic seizures, for dipsomania is usually associated with an epileptiform condition. This craving for alcohol was exhibited in true maniacal form ; for twentyseven days of the month he did not care anything about alcohol, during the remaining three days he could hardly be kept away from it. One other published case of double personality showed in the normal state a great craving for alcohol. In the case of Louis V., Mr. Meyer ${ }^{1}$ says: "Though he had before the attack been a total abstainer, he now not only drank his own wine but stole the wine of other patients." The effects of alcohol appear to satisfy some abnormal nervous conditions in the morbid state. The fact that to the disordered judgment it seemed right for him to take alcohol at that time, means little more than that he felt the need, and he justified himself in this manner. Of course he did not recognize that it was simply a physical craving, for it had been woven into the diseased consciousness in the form of an ethical judgment. Two further abnormalities connected with his dipsomania and the hypnotic state, were the delay in action (he drank two glasses of beer without any discomfort) and the reappearance of the suggestions in conscious memory when they became active. Usually the subject who goes as deeply asleep as John did, when he takes the first glass of alcoholic beverage becomes nauseated at once, not knowing why, and not remembering any suggestion which had been given him. Here we see a closer bond as far as memory is concerned, between the normal state and hypnosis, than between the normal and the abnormal states; but this may be accounted for on the theory advanced by some,

' 'Multiplex Personality,' Proc. Soc. Psy. Research, IV., 496. 
that when the post-hypnotic action in obedience to the command of the hypnotic state is carried out, there comes a temporary hypnotic condition during the time occupied in observing the command.

3. The phenomenon of repeating his awakening signal after he had awakened, without ability to stop, is interesting but not unique. In some experiments in automatic writing and other automatic movements, when the movements had been induced by repeated action, they would continue, after all initiative had been withdrawn, sometimes over one hundred times. ${ }^{1}$

4. The form of this case, as far as memory is concerned, is not unique, although usually the memories are entirely distinct. In the second state of Félida (there were three separate states), a case studied by Azam, the identical conditions of memory between the normal and abnormal states were found.

5. The predisposing cause of the abnormal states was undoubtedly epilepsy. The exciting cause was complex. One thing which contributed was the continuous study under unfavorable conditions; this put such a strain upon his mind that his brain and whole nervous system were affected. Another contributing exciting cause was his eyes. The cataracts directly did not affect the case to any appreciable extent, but indirectly they did. The cataracts were in the center of the lenses, and he endeavored to look around them. To accomplish this he walked along with his head down and eyes turned up, causing a heavy strain on the muscles of the eyes, and thereby putting himself in the position used by Braid and others in hypnotizing. The likeness of the abnormal state to the hypnotic trance would confirm us in placing this as a very important exciting cause, and in positing the case as closely allied to autohypnosis. Notice the similarity. First, he passed into the state as a hypnotic subject might do ; at first in the form of a sleep, taking some time in getting well asleep. At these times he was only suggestible. As he became more and more accustomed to it, he went to sleep much quicker until he passed into the abnormal state instantaneously; he also became more spontaneous, not waiting for suggestions, but doing things on his own initiative.

'A. Binet, 'Alterations of Personality,' pp. $98 f_{4}$ ' 
Second, a loss of memory of what happened in the abnormal state, but full memory of both states when in the abnormal state. Third, his suggestibleness. Coupled with this is his dramatic skill under suggestion. Fourth, the exaltation of his normal powers while in this abnormal state; this has been referred to in another connection.

6. The chief interest in this and similar cases must center around the question of personality. There has been considerable written lately by certain psychologists, concerning a hypothetical entity called by various names, e. g., ' Subliminal Self,' 'Subconscious Self,' 'Soul,' 'Other Self,' 'Second Personality,' 'Real Ego,' etc. The story is bruited abroad, that although the self and this mysterious individual of many names are keeping house together, they are not always congenial. According to some persons who claim to have seen her, she is sly, tricky, difficult to approach, murderous and thoroughly untrustworthy. Others affirm that she is very good, pure and refined, and that she will live after the death of the body and the self, $i$. e., that she is the soul of man. If one were asked to decide between these two contradictory statements, and to say which one is correct, he might well say, "Both, it depends on the company which she keeps, it depends on the person with whom she lives." Unfortunately for those who desire to multiply mysteries, she does not exist, it is all gossip. A large amount of the material which has been presented on this subject lately, has been very pernicious in interfering with the integrity of the self. If there is more than one self there are not less than ten thousand selves residing in the one body, and dependent upon one brain and nervous system.

Binet ${ }^{1}$ gives the distinguishing characteristics of selves as two in number, memory and character. Character implies so much that these two can be accepted as the dividing points. Let us look first at the connection between memory and personality. Can we say that we can be the same persons without self-conscious recognitive memory? $\mathrm{Or}$ is it necessary to remember all past experiences in order to be the same person? The ideal person holds a middle position between the two, for with no one person is either experience complete. In the life

\footnotetext{
'AAlterations of Personality,' p. 345.
} 
of everyone, there are certain mental experiences of whose validity we are in doubt when they come before us in memory; they may be dreams or they may be some of those strange experiences classed under what we call paramnesia. Is it memory, or is it imagination? The past alone holds the secret. Or it may be that it is impossible to tell whether or not we remember a certain experience as happening to us; and the question may come, in regard to some events, is it memory of the events as others have related them, or as they have really happened to us. Take the example of childhood experiences; our mothers have related the incidents so frequently, and we have retold them a number of times, until it is doubtful if we really remember them as experiences to the self. On the other hand, we must have some certain recognitive memory. What does it mean to be the same self without some recognitive memory? Yet to say that this must be continuous and complete is overstepping the mark on the other side.

We all recognize that one requisite of a good memory is the ability to forget well. The ideal person must forget eclectically. To remember every detail of life would so clog our minds as to render us unfit for the duties of life. We recognize this abnormality in some; the details are remembered so thoroughly that the important things are left out, and the individual is therefore unfitted for the responsible duties. So we swing from this extreme also; to be one and the same person it is not necessary to remember all of our past experiences.

But those who posit multiple personalities claim that it is the system of memories that makes the difference. A. B. remembers all the events of periods $I, 3,5,7, \ldots$ of his life at a certain time 9 ; but at to he only remembers the events of periods $2,4,6,8, \ldots$ At xo, or any period of even numbers, he cannot remember any events of period $I$ or any period of odd numbers; and at the odd periods the events of the even are equally shut out from him. This of course is the extreme case, and it is affirmed that in periods $x, 3,5,7, \ldots$ he is a different person from what he is during periods $2,4,6,8, \ldots$

Let us take a more familiar example. At nine o'clock in the evening I remember to mail a letter which my wife gave 
me for that purpose this afternoon. I remembered about mailing it at four o'clock and six o'clock when I was not near a letter-box, but at five o'clock and seven o'clock when I passed the postoffice and the associations might be considered more favorable for remembering, the matter was not present in consciousness. Now, am I the same person which had possession of my anatomy at four o'clock and six o'clock, and a different person than the one which had charge at five and seven? But, you object, that is only a case of spontaneous memory; your thoughts were busy with other things at five and seven; it was not that you could not possibly remember it if you had been asked concerning it. That is very true, but after all, that difference is but one of degree. We would not have to imagine much to suppose that if my wife were riding past the postoffice with me, and should ask if I had mailed the letter, that for a time I could not remember and should reply, "What letter?" and not until I had thought for some time could I remember it. This is a very simple example of lapse of memory, yet it differs only in degree from those lapses that are supposed by some to separate personalities. Examples without number could be given of total lapses of memory concerning certain subjects, under certain conditions, $e . g$., fatigue; under dissimilar conditions, e.g., rest and recuperation, the memory would be perfect.

Let us take another example; similar ones can be found in the lives of all. A gentleman after dinner sits down in his easy chair before the fire; his work is finished for the day, business is banished from his mind, and he thinks of the days of boyhood and young manhood. He thinks of his school-days in the 'old red school house,' - how familiar they are to him ! In thought he skips a few years of life as the preparatory school looms up before him, - how vivid it is. His freshman and senior years in college now take his attention, and from these he passes to the years in the law school. His memory has been concerned with only certain experiences, not continuous in time, but with years separating some, and nothing in between is recalled. During this time other memories have fled, and all events around him are unnoticed. He sees not the children as 
they pass through the room, he hears not the call of his wife; but when she arouses him sufficiently to ask a question concerning the events of yesterday, he is unable to answer it, and affirms that he does not remember, although in an hour's time, or after he has been further aroused, he may be able to answer the question fully and correctly. Is he a different person while sitting here and remembering only certain things, or is he the same person? This example illustrates a further truth : memory after all is a matter of associations, if the right spring can be touched the experiences can be remembered. In some cases the trouble is in touching the right spring.

One further example from a late work. ${ }^{1}$ A man drank quite heavily and went out driving with a friend. After a while the friend left him and he drove by a circuitous way back to the livery stable, stopped to allow another team to pass, delivered the horses, and went to a hotel some blocks away. Here he was aroused by a porter pounding on the side of a closet which he had entered. He remembered nothing of the past three hours. This was not a drunken sleep, for although he moved about apparently a trifle queer, he performed the complicated duties connected with the team in a competent manner, and went directly to the hotel. Was he a different person during these three hours? The memory of them was restored to him later by what is known as the hypnoid method.

Enough has been said to show what is wished - that memory, or lapse of memory (from whichever side we wish to view it), is a matter of degree, and depends on the control of the associations, and the coördination or harmony of the different elements of the personality. If necessary, a graded list could be gathered showing an unbroken line from the simplest lapse of memory to that which is supposed to separate personalities. Take four stages: (I) The common experience given above regarding the mailing of the letter. (2) The case given above of the abnormal state of the man who drank, but whose memory was afterwards restored. (3) The case of John Kinsel, who when in one state entirely forgot the events of the other state; but when in the other state remembered the events of

1 'Psycho-pathology.'-Boris Sidis. 
both states. (4) Common cases of 'double personality' where the memories of the two states are apparently entirely separated. Between these four we can fill in cases to make a gradual scale. Where is the line to be drawn between the amnesia of one person, and the distinction between two persons? How much would a person have to forget, and remember again under other circumstances, to become two persons? As has been suggested, ${ }^{1}$ we have been too willing to confuse amnesia with unconsciousness or other consciousness, instead of calling it what it really is, simply amnesia.

In dealing with the factor of character we have very much the same problem as we had concerning the memory, $i$. e., that of embracing separate and distinct states in one personality. It is claimed that in 'double personality' there is usually an entirely different character. Let us look at our characters after the analogy of chemical compounds, made up of varying quantities of certain identical or different elements. A few molecules more or less change the nature of the whole compound; the proportion between two or three elements may be changed only in one atom or molecule in a single element, and yet it makes the difference between a health-producing potion and a poison. Very little change in one element of the character causes such a difference in proportion that the whole character is altered from a brilliant, joyful, buoyant one, to a dull, morose, depressed one. Thus in laying emphasis on the great change of character in people, let us realize that in reality it may only be small and apparently insignificant after all.

The secret of character is control. A person has a real, true character only as he has real control, and he lacks this character as he lacks control. We found with Mr. Kinsel that his surliness in the secondary state was largely a matter of control. In the abnormal state he was particularly disagreeable to those whom he disliked normally, but who never knew it because then he was able to control himself. With other cases of 'double personality' there may seem to be a great change of character, but it could probably be traced to the lack of control in some one element of life.

' Psycho-pathology.'-Boris Sidis. 
Let us present two examples, both of which apply to the memory as well as to the character. A man is insulted and gets angry; contrary to his usual actions he talks loudly, calls vile names, swings his arms, and makes threatening gestures. His friends restrain him and take him away. The next day he is entirely ignorant of the details of the encounter; he denies that he swung his arms or talked loudly. Here is a lapse of both character and memory, but is the man a different person therefore, or is he the same person in a different mood?

The other example is more closely allied to 'double personality'; it is that of dreams. A very small proportion of our dreams are remembered for longer than a minute after waking; then they are gone beyond recall, and probably the great mass of our dreams are not remembered at all. For the time that we do remember them, and in those that we remember more fully, do we not recognize that $W E$ dream so and so, and not that someone else has dreamed them and communicated them to us? We recognize ourselves in our dreams, the experience happened to us. Our characters are entirely changed in dreams; we do things that we could not normally allow ourselves to do. Here, as is true with all character, it is a matter of control; our characters are less because we have less control, less will. Sometimes the dreams are forgotten and we are unable to recall them, but on successive nights the dreams may be taken up and continued so as to make a systematized experience, as in the case of Mr. Kinsel, yet we may be unable to recall the details, only remembering that the dreams are continued. In all this we do not recognize another personality; even if memory and character fail us, we still recognize the same personality as in the normal state.

We have found memory to be a matter of degree, ranging in a graded scale from simple amnesia to that separation of memories common in 'double personality.' Even here we do not admit a complete separation of memories, but only an apparent one. Certain states of one condition greatly influence the states of the other condition, and memory in a small degree is undoubtedly present. Some time ago it was thought that the deeper stages of hypnosis were entirely shut off from the nor- 
mal states as far as memory was concerned, but now it is recognized that the memory although weak is not entirely absent; and this we would posit for all cases of 'double personality' whether artificially induced or not. We have found character dependent on the amount of control, and therefore also a matter of degree; adding these distinguishing characteristics together, we would thus suggest that personality is a matter of degree. It is not a question then of the number of personalities, but of the degree of personality according to the amount of control and harmony. Therefore the term 'double' or 'multiple' personality has no real meaning, but instead we must state the particular stage of personality, ranging from complete or perfect personality to that of absence of personality, the extreme stages being purely hypothetical, and not found in real life. The very essence of personality is unity, and thus the term 'double personality' is a paradox; leave out unity and you destroy personality, and in proportion as unity is destroyed, personality is annihilated, not multiplied.

But a real objection enters here. One says, "I agree that personality is a matter of degree, that as memory loses and character loses, so personality loses; as the life is cut short in these respects, so the personality is dwarfed. Grant this, but what will you do with the separated portions? This is the whole question. When they are pieced together do they not make another personality in their systematized form?" No, we hold to our original suggestion. We doubt the complete change of character, at most it is only partial ; and we also doubt that these memories are completely cut off. There is some disassociation, but we would warn again against the confusion of amnesia with other consciousness. It is but an exaggeration of the common working of association. The mention of one book leads us to the consideration of one line of topics, while another name would lead us in the opposite direction. These would never cross, one would never lead to the other. If a common association could be obtained, the two lines of thought could be merged. We find this well illustrated in hypnosis; in the deeper stages there is little or no memory when the subject awakes. Experiments of this kind have been tried: let the 
subject be awakened when he is washing his hands, or performing some act that can be continued, and the hypnotic experiences are remembered. Here the common association is found, and instead of two personalities we find only one; had not this association been found there would still be only one personality, dwarfed by simple amnesia. Successfully have the amnesic experiences been recalled by hypnotic and allied methods, and no distinct personalities have been found, but the same personality suffering from amnesia, a certain group of facts awaiting the proper stimuli to be aroused. We then would say in answer to the objection, we have no second personality, but the same personality which, like all other persons, is able to recall certain events under certain stimuli and associations, and when other stimuli and associations act, then other events come to mind; a stimulus or association common to both trains of associations would arouse both streams of thought of this one person.

We would suggest also that what sometimes seems like another personality is the mechanical action of the physical processes. 